\title{
Seismic Assessment of Structures in Regions of Low to Moderate Seismicity
}

\author{
Lumantarna, E. ${ }^{1}$, Lam, N. ${ }^{1}$ and Wilson, J. ${ }^{2}$
}

\begin{abstract}
Assessment of structures according to conventional seismic design procedure has been based on trading off strength and ductility (or displacement) to provide sufficient energy dissipation capacity to structures. Consequently, structures in regions of high seismicity are designed to undergo large displacements whilst maintaining their lateral strengths in an earthquake. Energy demand from a small to medium earthquake could subside with increasing effective natural periods. Significantly, the amount of drift imposed on the structures could be restrained to an upper limit irrespective of the degradation in strength or stiffness of the lateral load resisting elements. Based on the displacement-controlled behaviour, structures can be deemed seismically safe despite having undergone significant degradation in strength and stiffness, provided that the structures can sustain the maximum drift demand from an earthquake without collapsing. This paper proposes a simple procedure for the assessment of structures in regions of low to moderate seismicity. The proposed procedure will result in significant savings in time and costs particularly when a large number of structures are to be assessed for their potential vulnerability in an earthquake.
\end{abstract}

Keywords: Seismic assessment, non-ductile structure, displacement demand, earthquake.

\section{Introduction}

Current seismic design and assessment procedures are founded on the concept of trading-off strength with ductility to ensure that the structures have sufficient capacity to absorb energy from an earthquake and dissipate it in a controlled manner. As a result, structures in high seismicity regions are designed to undergo large displacements whilst maintaining their lateral strengths in an earthquake. The structures are deemed to fail when their strengths have degraded such that their energy absorption capacities have been overcome by the energy demand.

Recent studies have highlighted that the energy demand of a small to medium magnitude earthquake could subside as the strength and stiffness of a structure has deteriorated [1]. Most importantly, the structure will only be displaced to a certain limit, as illustrated in Figure 1 by the displacement response spectra of a single pulse and series of periodic pulses (representing resonance condition on flexible soil sites). Consequently, the "trading-off" concept between strength and ductility (to provide sufficient energy absorption capability) will result in a conservative prediction of seismic performance of structures in term of their ultimate survival in the event of an earthquake.

${ }^{1}$ Dept of Infrastructure Engineering, The University of Melbourne, Parkville, VIC 3010, AUSTRALIA. Email: elu@unimelb.edu.au ${ }_{2}^{2}$ School of Engineering and Industrial Science, Swinburne University of Technology, Hawthorne, VIC 3122, AUSTRALIA.

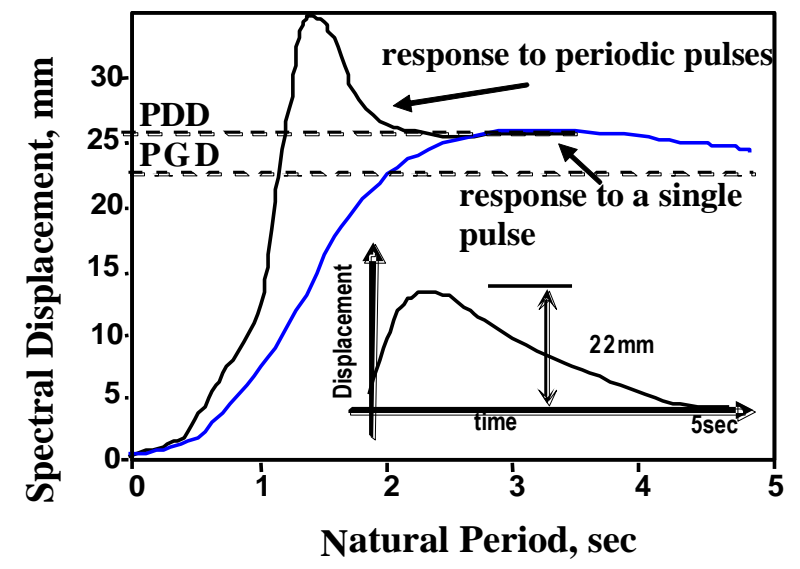

Figure 1. Displacement-controlled Behaviour [1]

An assessment based on a comparison of displacement demand with displacement capacity is a more realistic and effective approach in the evaluation of the seismic performance of a structure. A structure with significant strength degradation can be deemed seismically safe if the displacement demand can be accommodated whilst the structure still maintains its gravitational load carrying capacity.

This paper introduces a simple method for the seismic assessment of structures based on the displacement-controlled behaviour. The seismic assessment requires the displacement capacity of structures to be compared directly with displacement demand for a rapid assessment of its potential vulnerability in an earthquake. A generalised and 
idealised response spectrum model in the displacement format is introduced in the following section. The displacement response spectrum can provide estimates of the displacement demand behaviour of simplified (elastic single-degree-of-freedom system) structural models when subject to an earthquake ground shaking. Parametric studies were undertaken involving non-linear time history analyses of inelastic systems with and without strength degradation (Section: Inelastic Displacement Demands of Non-Ductile Structures). Parametric studies on asymmetrical buildings have been conducted to extend the concept of displacement-controlled behaviour to structural systems that are subject to torsional actions (Section: Displacement Demands of Asymmetrical Buildings).

\section{Bi-Linear Displacement Response Spec- trum}

In this study, the proposed displacement response spectrum is presented in bi-linear format (Figure 2). The proposed displacement response spectrum is truncated at the limiting period of $5 \mathrm{~s}$. The estimated values of $R S D_{\max }$ based on the period rangeofup to $5 \mathrm{~s}$ has been used for the stability assessment of a wide range of structures, such as free standing objects $[2,3]$, unreinforced masonry walls $[4,5]$ and softstorey structures [6]. The displacement response spectrum on rock sites is defined by Equation 1 .

$$
\begin{aligned}
& R S D(T)=\frac{R S D_{\max }}{T_{2}} T \text { for } T \leq T_{2} \\
& R S D(T)=R S D_{\text {max }} \text { for } T>T_{2}
\end{aligned}
$$

where the value of $R S D_{\max }$ is the peak displacement demand and $T_{2}$ is the second corner period.

Extensive parametric studies have been undertaken by the authors [7] involving eight well known ground motion predictive models and 168 accelerograms sourced from the PEER database (available for public access via the worldwide web at $<$ http://peer. berkeley.edu/nga/>). The parametric studies revealed that the estimated (median) values of the $R S D_{\max }$ parameters by the different models are highly consistent except for earthquakes at short distances.

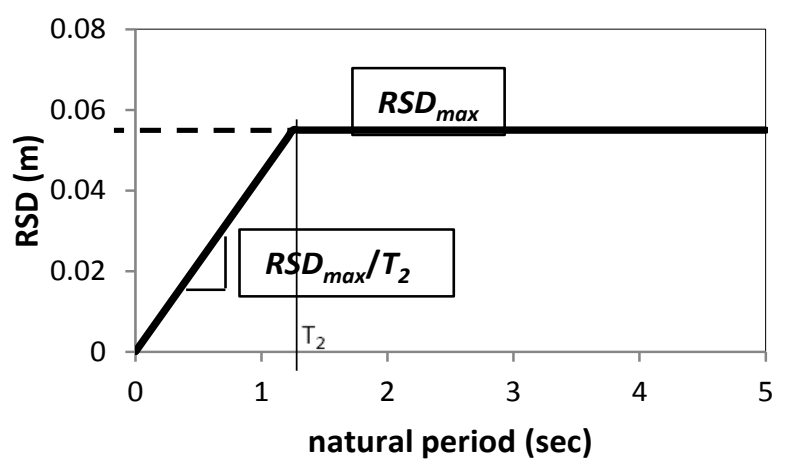

Figure 2. Displacement Response Spectrum in the Bilinear Format
Table 1. Median Model Predictions of Peak Displacement Demand $R S D_{\max }(\mathrm{mm})$

\begin{tabular}{cccccc}
\hline & $\begin{array}{c}\mathrm{R}=10 \\
\mathrm{~km}\end{array}$ & $\begin{array}{c}\mathrm{R}=20 \\
\mathrm{~km}\end{array}$ & $\begin{array}{c}\mathrm{R}=30 \\
\mathrm{~km}\end{array}$ & $\begin{array}{c}\mathrm{R}=40 \\
\mathrm{~km}\end{array}$ & $\begin{array}{c}\mathrm{R}=50 \\
\mathrm{~km}\end{array}$ \\
\hline M5.5 & 23 & 15 & 10 & 8 & 5 \\
& $(15-30)$ & $(10-20)$ & $(5-15)$ & & \\
M6 & 68 & 34 & 20 & 15 & 10 \\
& $(45-90)$ & $(25-40)$ & $(15-25)$ & & \\
M 6.5 & 135 & 75 & 55 & 38 & 33 \\
& $(90-180)$ & $(55-90)$ & $(45-60)$ & $(30-45)$ & $(25-40)$ \\
\hline Notes: & & & & &
\end{tabular}

(a) Mid range values are shown.

(b) Upper and lower bound values are shown in brackets where there are significant inter-model discrepancies.

(c) Values shown in italics are much less well constrained and are associated with scenarios of very low probability of occurrences in a region of low-moderate seismicity.

The mid-range values (along with the upper bound and lower bound values) predicted by the suite of models for various magnitude-distance combinations are shown in Table 1 . The predicted values have been validated by comparison with the values of $R S D_{\max }$ calculated from 168 accelerograms obtained from PEER database [7].

In contrast, the value of $T_{2}$ is not unique and is well known to be sensitive to the moment magnitude of the earthquake. The predictions of $T_{2}$ values from the available predictive models [8-11] are very diverse. However, parametric studies conducted by the authors [7] that Equation 2 proposed by Lam et al. [11] is consistent with field observations.

$T_{2}=0.5+\frac{M-5}{2}$

where, $M$ is the moment magnitude of the earthquake.

The maximum displacement demand $\left(R S D_{\max }\right)$ in more onerous soil conditions can be significantly amplified. Parametric studies were undertaken based on shear wave analyses. A total of 1600 accelerograms on rock, shallow and deep soil sites were generated based on magnitude and epicentral distance combinations producing peak ground velocity $\mathrm{PGV}$ on rock which ranges from 20 to $100 \mathrm{~mm} / \mathrm{s}$. The accelerograms on rock sites were generated by stochastic simulations using program GENQKE [12]. The accelerograms on rock sites were used as inputs in soil dynamic response analysis program SHAKE [13] to simulate accelerograms on shallow and deep soil sites. The range of PGV is consistent with hazard factor $\mathrm{Z}$ of 0.03 to 0.12 which is representative of seismic hazards in most capital cities in Australia, including Melbourne, Sydney, Canberra, Adelaide, and Perth for 50 to 2500 year return period. For each of the simulation, the value 
of the site amplification factor (S) was calculated by dividing the maximum displacement response spectrum on the shallow and deep soil site $\left(R S D_{\text {max,soil }}\right)$ by the value of response spectral displacement on the rock site at the site period $\left(R S D_{\text {rock }}\left(T_{2, \text { soil }}\right)\right)$ as shown schematically in Figure 3. It was found from the site response analyses that values of the site amplification factor generally range between 3 and 5 .

Based on the findings from the parametric studies, Equation 3 is proposed to define the displacement response spectrum model on a soil site.

$R S D(T)=\frac{R S D_{\text {max }, \text { soil }}}{T_{2, \text { soil }}} T$ for $T \leq T_{2, \text { soil }}$

$R S D(T)=R S D_{\max , \text { soil }}$ for $T>T_{2, \text { soil }}$

where, $R S D_{\text {max soil }}$ can be estimated as:

$R S D_{\text {max }, \text { soil }} \approx R S D\left(T_{2, \text { soil }}\right) 4$

where, $R S D\left(T_{2, \text { soil }}\right)$ is the response spectral displacement defined by Equation 1 .

\section{Inelastic Displacement Demands of Non- Ductile Structures}

This section presents findings from parametric studies involving non-linear time-history analyses of inelastic systems to provide estimates of the peak

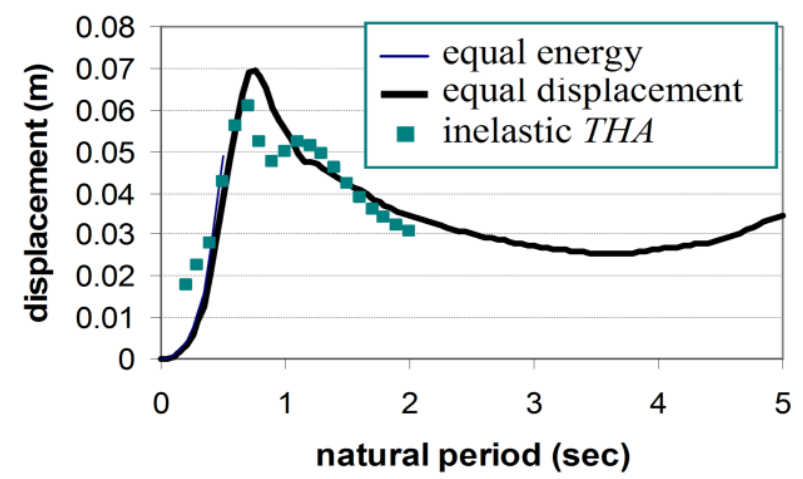

(a) $R_{\mu}=2$ without strength degradation

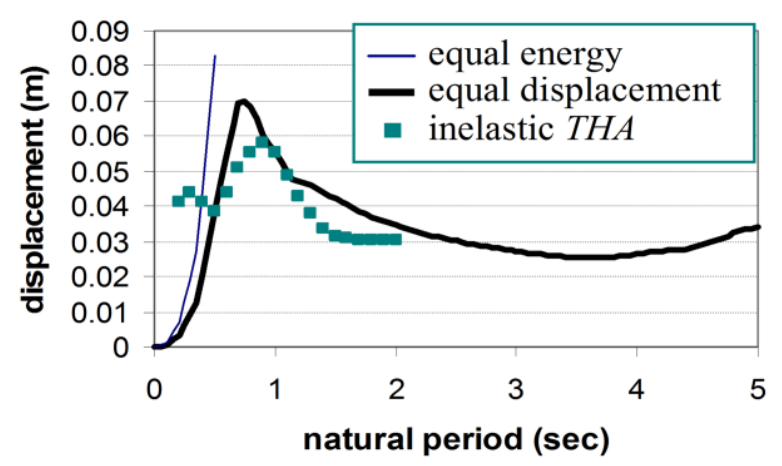

(c) $R_{\mu}=4$ without strength degradation displacement demands of non-ductile structures [6]. Hysteretic models used in the studies represent the hysteretic behaviour of non-ductile structures, such as unreinforced masonry buildings and soft-storey structures. The hysteretic models used feature both stiffness and strength degradation. Details of calibration of the hysteretic models and the accelerograms used in the parametric studies can be found in Lumantarna et al. [6].

The maximum inelastic displacement demands of single-degree-of-freedom ( $S D O F)$ systems with $R_{\mu}=2$ and 4 as obtained from time-history analyses are presented in Figure 4. All the analyses featuring strength degradation were based on 15\% degradation in strength per unit increase in the value of $\mu$.

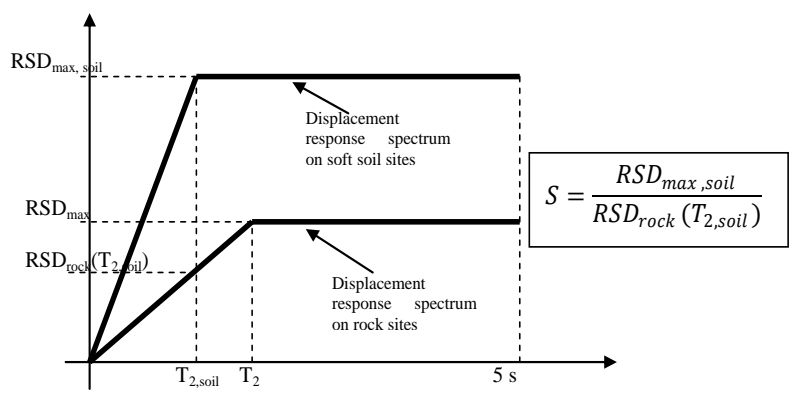

Figure 3. Displacement Response Spectrum on Soil Site

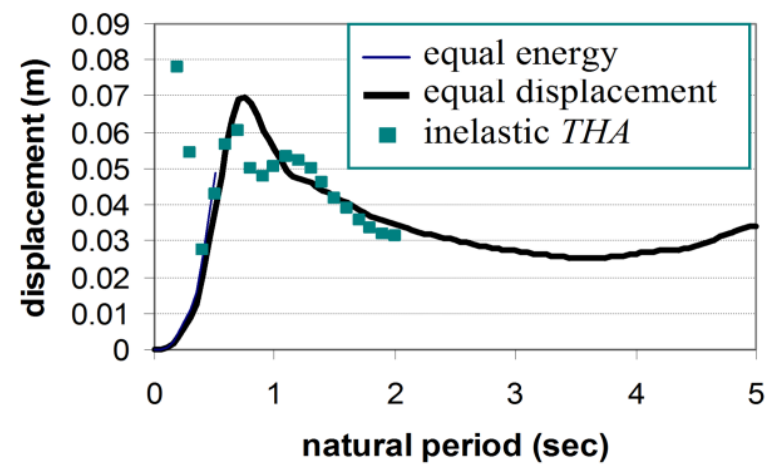

(b) $R_{\mu}=2$ with strength degradation

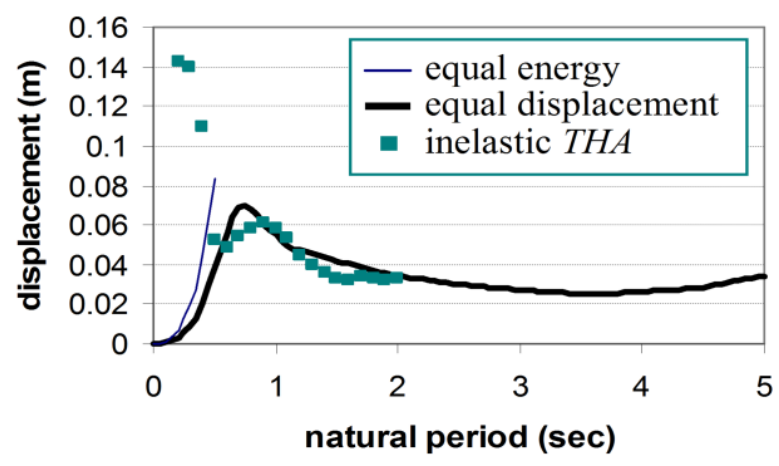

(d) $R_{\mu}=4$ with strength degradation

Figure 4. Elastic and Inelastic Displacement Demands with Friuli Earthquake 
In the displacement sensitive region of the response spectrum (ie. $T>T_{2}$ ), the elastic displacement demand values (as represented by the lines in the figures) were approximately equal to or exceed the calculated inelastic displacement demand values (as represented by the symbols in the figures) in all the cases presented. In the acceleration and velocity sensitive ranges of the response spectrum, $\left(T<T_{2}\right)$, the elastic displacement demand values is significantly exceeded by the inelastic displacement demand values. The displacement demand behaviour depends very much on the corner period parameter which characterises the frequency properties of the ground shaking. However, it was found that with a modest strength reduction factor of 2 , the system's inelastic displacement demand would typically be constrained by the peak displacement demand $(P D D)$ which is defined by the maximum point on the elastic displacement response spectrum for 5\% damping $\left(R S D_{\max }\right)$ irrespective of the initial natural period of the system.

Further parametric studies were undertaken considering systems characterised by the value of $R_{\mu}=2$ and 4 and rate of strength degradation varying between $0 \%$ and $25 \%$ per unit value of $\mu$. Results from the analyses were sorted into groups according to ratio of the initial period of the non-linear models to the $2^{\text {nd }}$ corner period (i.e. ratio of $T / T_{2}$ ). The statistics of the displacement demands as observed from the time-history analyses were analysed to identify the proportion of cases in which the peak displacement demand $(P D D)$ limit (which is defined as the highest point on the elastic displacement response spectrum for $5 \%$ critical damping) was exceeded. Fragility curves were then constructed to correlate the cumulative probability of exceedance with the rate of strength degradation (Figure 5).

Overall, the inelastic displacement demand values were generally well constrained by the $P D D$ limit provided that $T>T_{2}$ and that the rate of strength degradation was less than $15 \%$ per unit increase in the ductility demand ratio $(\mu)$ (Figure 5). The robustness of the $P D D$ as a constraint of the system displacement demand is well demonstrated, but the value of the $T / T_{2}$ ratio is critical to the reliability of the constraint. However, it is shown that with a modest strength reduction factor $\left(R_{\mu}\right)$ of 2 , the inelastic displacement demands were constrained within the $P D D$ limit, irrespective of the $T / T_{2}$ ratio, provided that the rate of strength degradation is within $10 \%$ per unit increase in the value of $\mu$.

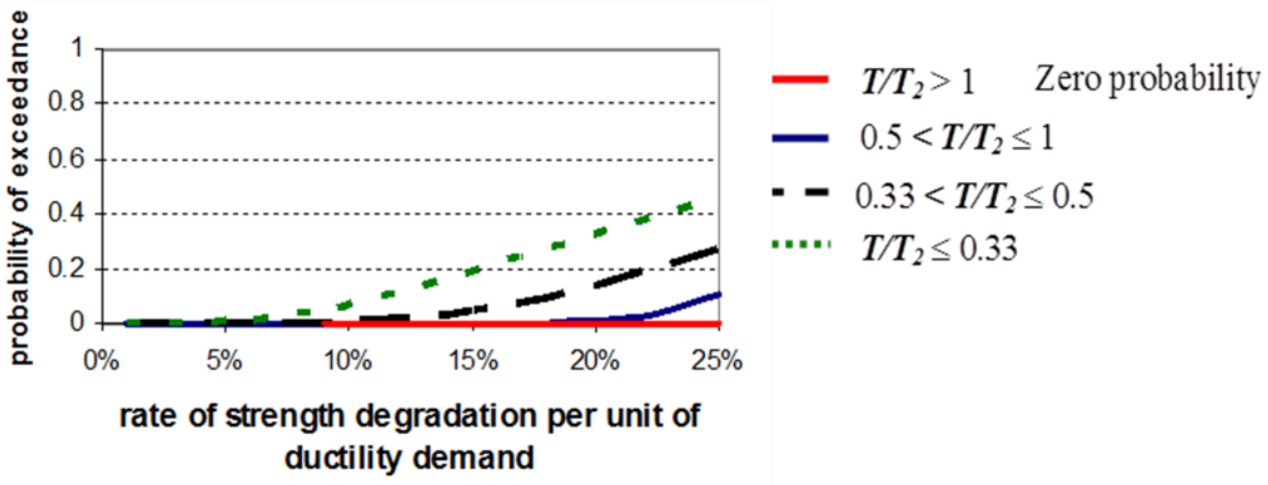

(a) $R_{\mu}=2$

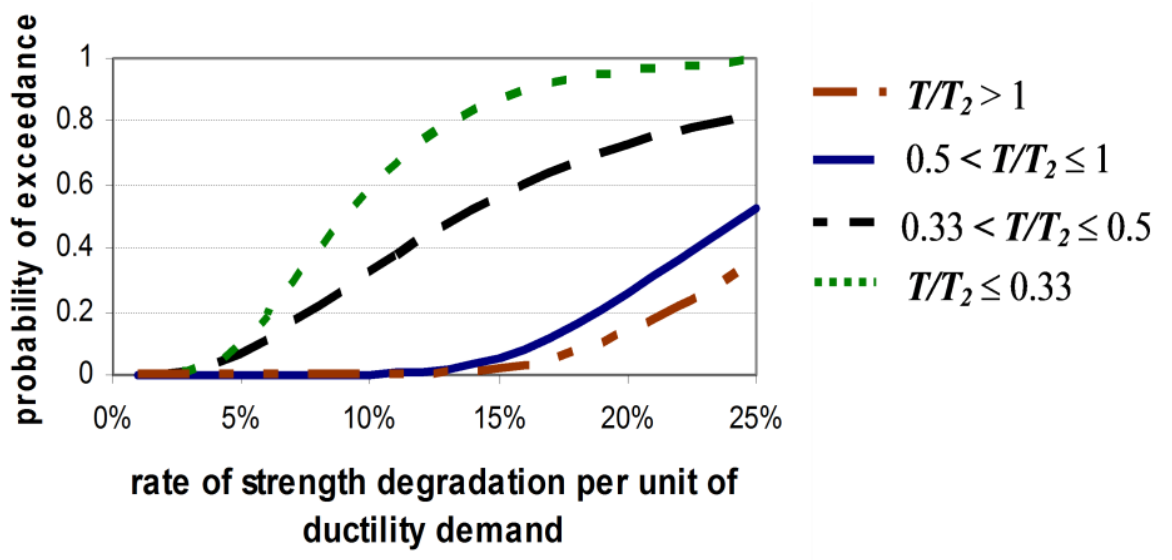

(b) $R_{\mu}=4$

Figure 5. Probability of Exceedance for PDD 


\section{Displacement Demands of Asymmetrical Buildings}

In situations where the center of resistance (CR) of the building does not coincide with the center of mass (CM) (Figure 6a), the building will translate and rotate when subject to earthquake excitations. The translation and rotation can result in displacement amplification at the edges of the building as shown in Figure 6b. It is postulated herein that the displacement demand on a torsionally unbalanced building could be constrained by an upper limit which is referred herein as the peak displacement demand $(P D D)$ value. The maximum displacement could occur at the flexible or the stiff edge of the building depending on the dominant mode of vibration. The peak displacement demand referred in this section represents the higher of the two values.

The peak displacement demand $(P D D)$ values of asymmetrical buildings have been estimated initially in this study using the response spectral analysis method assuming linear elastic behaviour. The displacement response of a torsionally coupled building can be determined by calculating eigenvalues and eigenvectors of the equation of motion as shown by Equation 4.

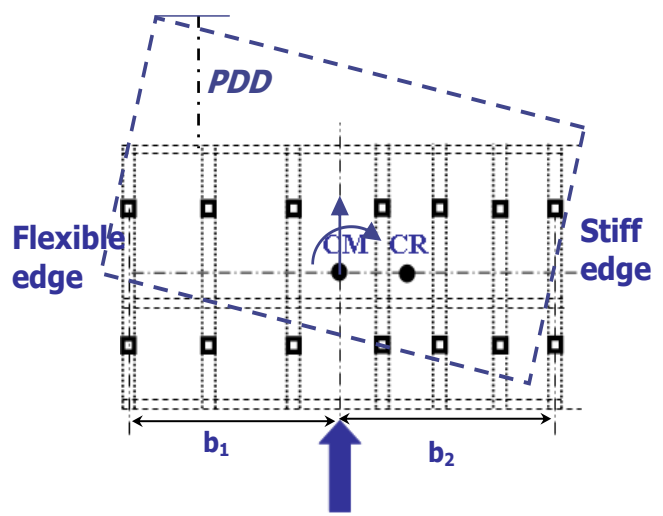

(a) floor plan

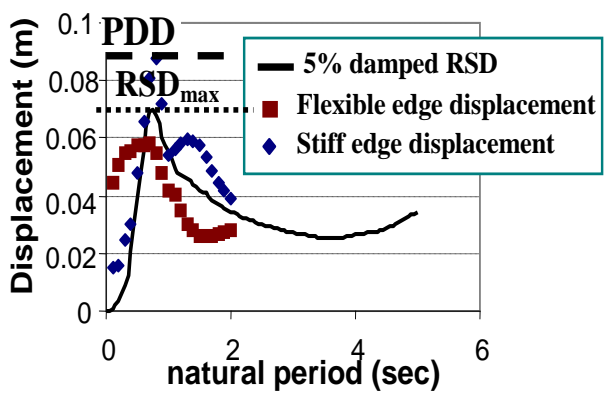

(b) Peak displacement demand

Figure 6. Amplification of Displacement Demands in an Asymmetrical Building $\left[\overline{\boldsymbol{k}}-\omega_{\mathrm{n}}^{2} \overline{\boldsymbol{m}}\right] \phi_{\mathrm{n}}=\mathbf{0}$

where $\omega_{\mathrm{n}}$ are the natural frequencies of a torsionally coupled building; $\phi_{\mathrm{n}}$ is the mode shape vector which contains translation $\phi_{y \mathrm{n}}$ and $\phi_{\theta \mathrm{n}}$ components of the $\mathrm{n}^{\text {th }}$ mode of vibration; $\overline{\boldsymbol{k}}$ and $\overline{\boldsymbol{m}}$ is the stiffness and the mass matrix respectively, as defined by Equation (5).

$\overline{\boldsymbol{k}}=\left[\begin{array}{cc}k_{y y} & e_{s} k_{y y} \\ e_{s} k_{y} & k_{\theta \theta}\end{array}\right]$

and

$\overline{\boldsymbol{m}}=\left[\begin{array}{cc}m & 0 \\ 0 & r^{2} m\end{array}\right]$

where $k_{\mathrm{yy}}$ is the total lateral stiffness of the building; $k_{\theta \theta}$ is the torsional stiffness about the center of mass; $m$ is the mass; $r$ is the mass radius of gyration and $e_{\mathrm{s}}$ is the offset of the center of resistance from the center of mass.

Having determined the natural frequencies and the mode shapes of vibration, the contribution of the $n^{\text {th }}$ mode $\left(u_{n}\right)$ of vibration to the total displacement " $\mathrm{u}$ " of the building can be conservatively estimated by Equation 6 assuming a constant value of the displacement demand (which is the value of $R S D_{\max }$ as defined by Figure 2):

$u_{y n}=P F_{n} \emptyset_{y n} R S D_{\max }$

$u_{\theta n}=P F_{n} \emptyset_{\theta n} R S D_{\max }$

where $\phi_{y n}$ and $\phi_{\theta n}$ are the translational and rotational components of the $\mathrm{n}^{\text {th }}$ mode of vibration; $P F_{\mathrm{n}}$ is the participation factor of the $\mathrm{n}^{\text {th }}$ mode and $R S D_{\max }$ is the highest point on the elastic displacement response spectrum for $5 \%$ critical damping.

The displacement demand values at the flexible edge $\Delta_{\text {flex,n }}$ and stiff edge $\Delta_{\text {stiff,n }}$ of the building for the $\mathrm{n}^{\text {th }}$ mode of vibration can be expressed in terms of the translational and rotational displacement (as defined by Equations $7 \mathrm{a}$ and $7 \mathrm{~b})$.

$\Delta_{\text {flex }, n}=u_{y n}-u_{\theta n} b_{1}$

$\Delta_{\text {stiff }, n}=u_{y n}+u_{\theta n} b_{1}$

where $b_{1}$ and $b_{2}$ are the offsets of the flexible and stiff edge of the building respectively from its center of mass. The displacement at the edges of the building for each mode of vibration can be combined according to the square-root-of-the-sum-of-the square SRSS method or the complete quadratic combination (CQC) for torsional sensitive systems with closely spaced natural frequencies [14]. The trends obtained from the SRSS and CQC method are generally consistent, with the SRSS method being slightly more conservative. 
Using the SRSS combination rule, the value of $\Lambda_{\mathrm{DD}}$ can be obtained by the use of Equation 8:

$$
\Lambda_{\mathrm{DD}}=\text { larger of } \sqrt{\frac{\left(P F_{1}-\widehat{\theta}_{1} \frac{b_{1}}{r}\right)^{2}+\left(P F_{2}-\widehat{\theta}_{1} \frac{b_{1}}{r}\right)^{2}}{\left(P F_{1}+\widehat{\theta}_{1} \frac{b_{1}}{r}\right)^{2}+\left(P F_{2}-\widehat{\theta_{1}} \frac{b_{1}}{r}\right)^{2}}}
$$

and $P D D=\Lambda_{\mathrm{DD}} R S D_{\max }$

where $P F_{1}$ is the participation factor for the $1^{\text {st }}$ mode of vibration; $P F_{2}$ is the participation factor for the $2^{\text {nd }}$ mode of vibration $\left(=1-P F_{1}\right) ; \hat{\theta}_{1}$ is the rotational component of the $1^{\text {st }}$ mode $\left(\phi_{01}\right)$ multiplied by the mass radius of gyration $(r) ; b_{1}$ and $b_{2}$ are the offset of the flexible and stiff edge, respectively, of the building from its center of mass.

$P F_{1}=\frac{e^{2}}{e^{2}+\left(1-\Omega_{1}^{2}\right)^{2}}$

$\widehat{\theta_{1}}=-\frac{e\left(1-\Omega_{1}^{2}\right)}{e^{2}+\left(1-\Omega_{1}^{2}\right)^{2}}$

$\Omega_{1}$ is the $1^{\text {st }}$ coupled circular frequency which can be expressed as a function of the uncoupled natural frequency ratio $\left(\rho_{\mathrm{k}}=1 / r\left(k_{\theta \theta} / k_{y y}\right)^{1 / 2}\right)$ and offset of the center of resistance from the center of mass of the building normalised with respect to its mass radius of gyration (e). The value of $\Omega_{1}$ can be calculated using Equation 9c.

$\Omega_{1}=\frac{1+\rho_{k}+e^{2}}{2}-\sqrt{\frac{\left(1+\rho_{k}+e^{2}\right)^{2}}{4}-\rho_{k}^{2}}$

Values of $\Lambda$ DD presented in Figure 7 were calculated using Equations 8 and 9 for values of $e$ (eccentricity) varying between 0.1 to 0.8 , and $\rho_{\mathrm{k}}$ (uncoupled frequency ratio) varying between 0.6 to 1.6. An important observation from the figure is that the value of $\Lambda_{D D}$ is capped at around 1.5-1.6. It is implied from the presented results that the amount of torsional rotation in the building would not increase with increasing value of the eccentricity (e), nor with decreasing value of the torsional stiffness $\left(\rho_{\mathrm{k}}\right)$.

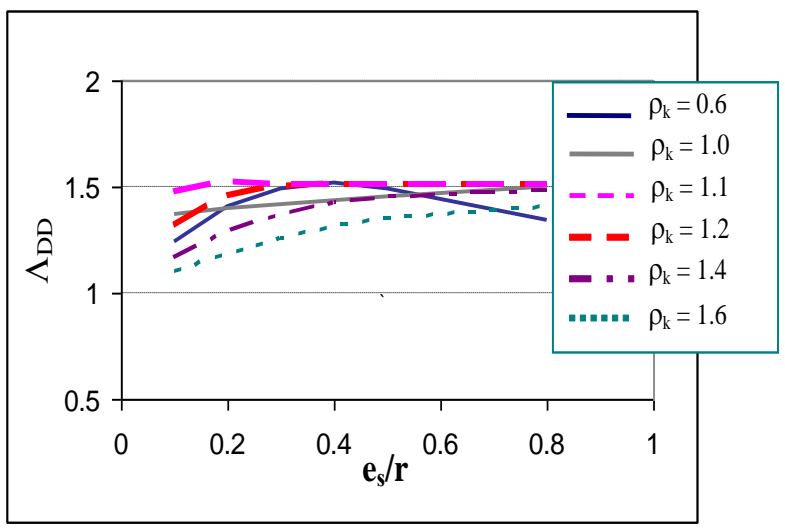

Figure 7. Torsional Amplification Factor $\Lambda \mathrm{DD}$ using Response Spectral Analysis
Results presented in Figure 7 have been validated further by parametric studies involving linear and non-linear time history analyses. The analyses reported herein were based on single-storey building models shown in Figure 6a. Every model consisted of a rigid floor which is supported by three lateral resisting frame elements. The initial stiffness of individual frames in the model was calibrated such that the uncoupled natural period of vibration of the building ranges in between 0.2 to $2 \mathrm{~s}$. Refer to Lumantarnaet al. [6] for details of accelerograms.

The $P D D$ value as defined by Equation 10 is identified by a (broken and bold) horizontal line on the respective displacement response spectrum in Figure 8. It is shown that the calculated maximum element displacements are all within the estimated limit ("the cap"). It is also shown that an increase in the value of the eccentricity ratio $(e)$ from 0.3 to 0.5 has not resulted in any significant changes to the element displacement demand.

$P D D=1.6 R S D_{\max }$

Parametric studies on the element displacement demand have been extended to cover torsionally unbalanced building models responding in the inelastic range. The notional yield strength of the individual frames $F_{y}$ were adjusted in order that the strength of each frame (calculated from $2 \mathrm{D}$ analyses neglecting torsional actions) was exceeded by the elastic strength demand by a factor $\left(R_{\mu}\right)$ of 2 to 4 .

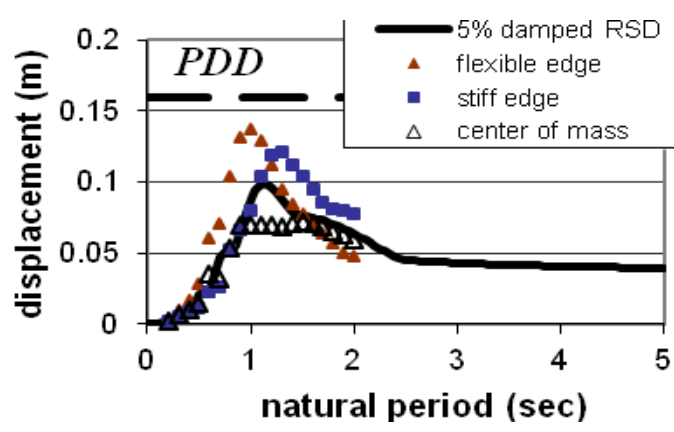

(a) $e=0.3, \rho_{k}=0.8$

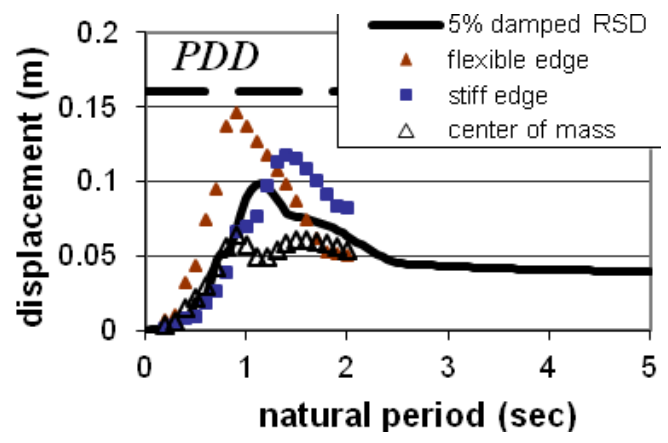

(b) $e=0.5, \rho_{k}=0.8$

Figure 8. Element Displacement Demand from Linear Time-History Analysis, San Fernando Earthquake 


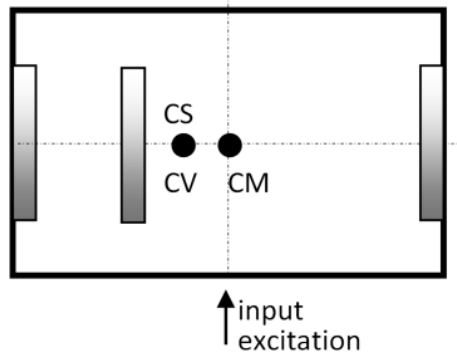

(a) Model A

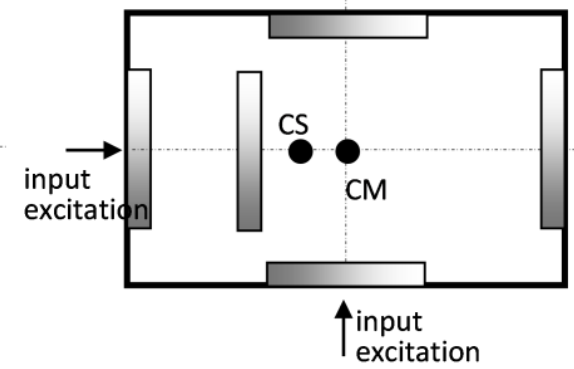

(b) Model B
CS - Center of Stiffness

$\mathrm{CM}$ - Center of Mass

Figure 9. Single Storey Building Model for Non-linear Time History Analyses

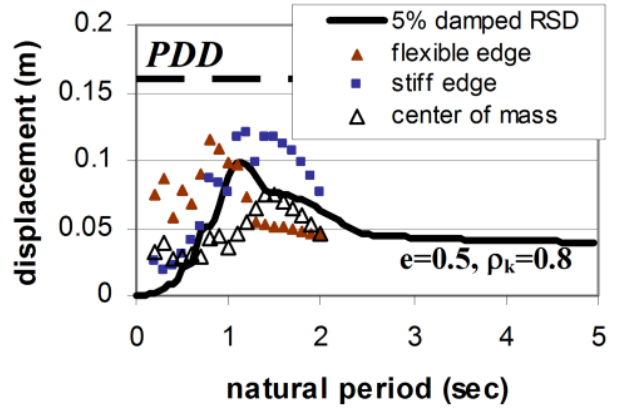

(a) without strength degradation, $R_{\mu}=2$

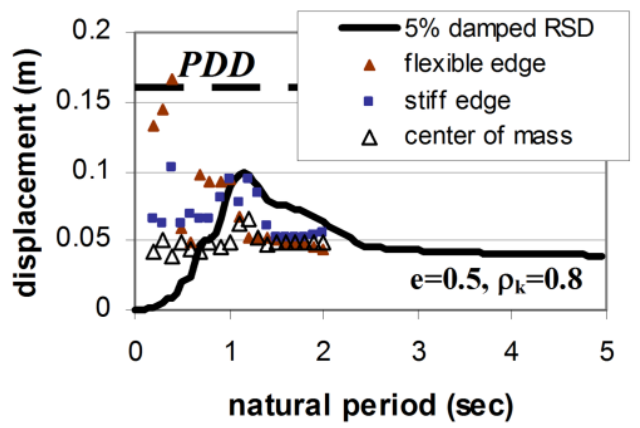

(c) without strength degradation, $R_{\mu}=4$

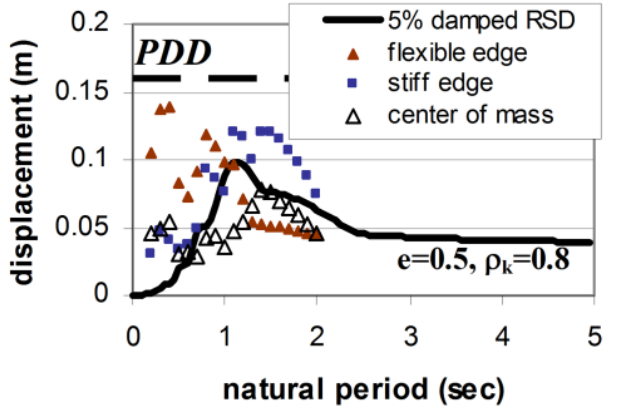

(b) with strength degradation, $R_{\mu}=2$

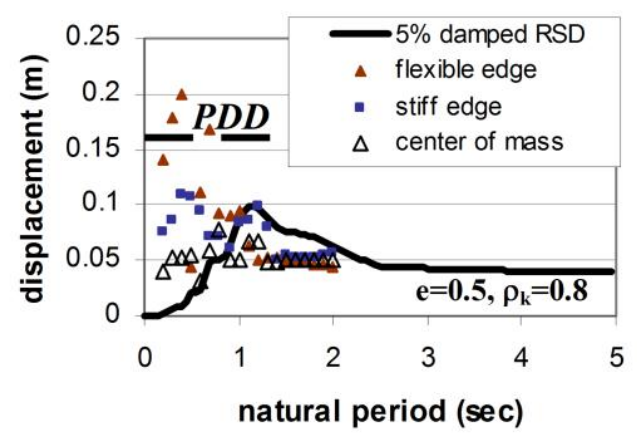

(d) with strength degradation, $R_{\mu}=4$

Figure 10. Element Displacement Demand from Non-linear Linear Time-history Analysis, San Fernando Earthquake

Consequently, the offset of the center of stiffness and center of strength of the building model from its center of mass is solely dependent on the location of the frames within the building (i.e. $\mathrm{CV}=\mathrm{CS}$ ) as shown in Figure 9a. All the analyses were based on $15 \%$ degradation in strength per unit increase in the value of $\mu$. Meanwhile, control analyses assuming no strength degradation had also been undertaken.

The maximum inelastic displacement demand on elements in asymmetrical buildings based on $R_{\mu}=2$ and 4 are presented in Figure 10 for systems with and without strength degradation. The element displacement demand values were all within the $P D D$ limit as defined by Equation 10, irrespective of the initial natural period of the buildings, provided that the value of $R_{\mu}$ factor had not exceeded 2 . Higher element displacement demand values were observed when a $R_{\mu}$ factor of 4 with strength degradation was applied.

The peak element displacement demand values of the simplified model (model A in Figure 9a) have also been compared with displacement values of a more realistic building model of orthogonal frames subject to bi-directional excitations (model B in Figure 9b). The uncoupled natural periods of vibration of the building in both orthogonal directions were assumed to be equal. The notional yield strength of each frame in the orthogonal direction (Figure 9b) had also been adjusted in order that the strength capacity of each frame was exceeded by the 
strength demand by a factor of 2 to 4 (ie. $R_{\mu}=2-4$ ). The building was subject to excitations of equal intensity in both directions.

Figure 11 shows correlation plots of displacement demand values of building models under uni-lateral and bi-lateral excitations. The displacement demand values of model $\mathrm{A}$ and model $\mathrm{B}$ were generally shown to be well correlated.

Model A presented in Figure 9a was used to conduct a more extensive parametric study which considered systems characterised by the value of $R_{\mu}=2$ and 4 and rate of strength degradation varying between $0 \%$ and $25 \%$ per unit value of $\mu$. The values of eccentricity $(e)$ and uncoupled frequency ratio $\left(\rho_{\mathrm{k}}\right)$ were varied from 0.1 to 0.5 and 0.8 to 1.3 , respectively.

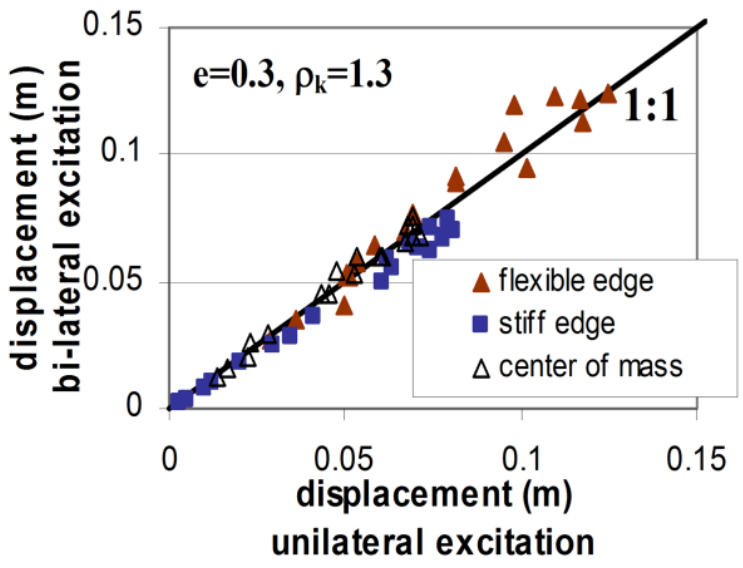

(a) without strength degradation, $R_{\mu}=2$

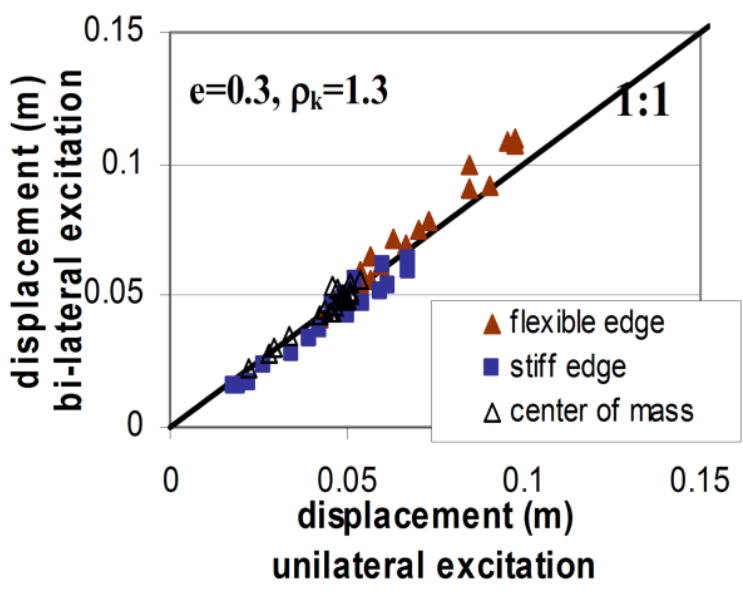

(c) without strength degradation, $R_{\mu}=4$
Results from the analyses were sorted into groups according to ratio of the uncoupled initial period of the non-linear models to the $2^{\text {nd }}$ corner period (i.e. ratio of $T / T_{2}$ ). Fragility curves as shown in Figure 12 were constructed to correlate the cumulative probability of exceedance with the rate of strength degradation. It is shown that the inelastic displacement demands were generally constrained by the $P D D$ limit. However, the value of the $T / T_{2}$ ratio is critical to the reliability of the constraint.

Importantly, it is shown that with a modest strength reduction factor $\left(R_{\mu}\right)$ of 2 , the inelastic displacement demands were constrained within the $P D D$ limit irrespective of the $T / T_{2}$ ratio provided that the rate of strength degradation is within $10 \%$ per unit increase in the value of $\mu$.

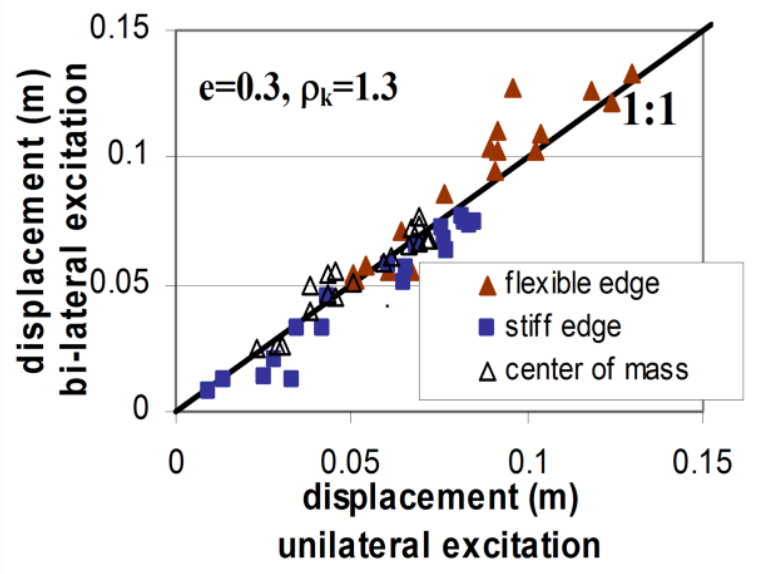

(b) with strength degradation, $R_{\mu}=2$

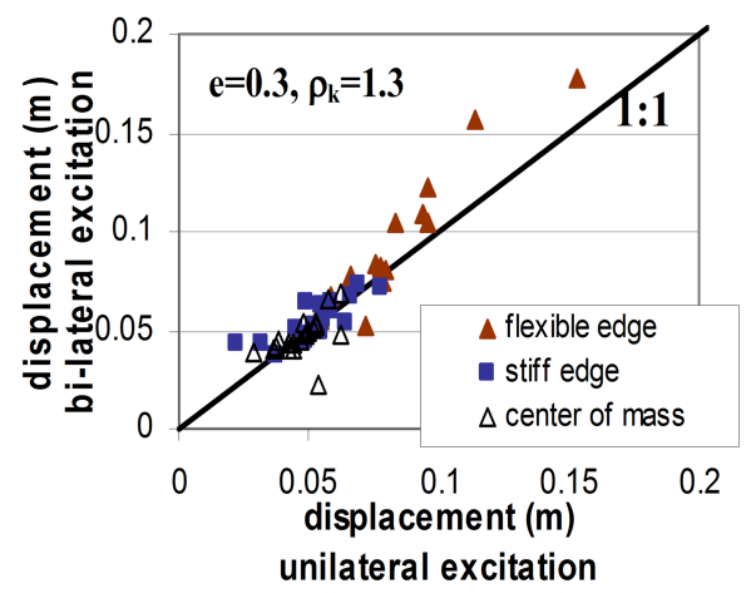

(d) with strength degradation, $R_{\mu}=4$

Figure 11. Displacement Demands of Building Model A Subject to Uni-lateral and Building Model B Subject to Bidirectional Excitations, San Fernando Earthquake 


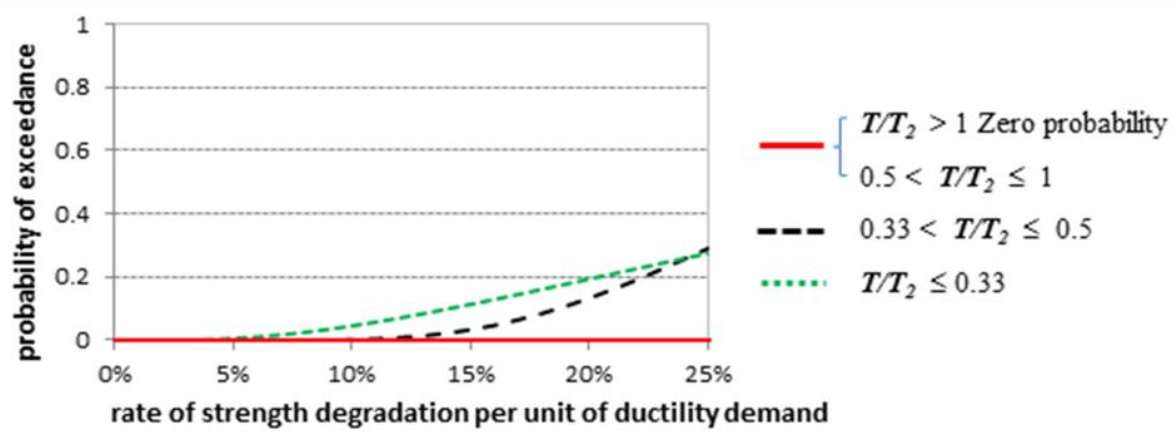

(a) $R_{\mu}=2$

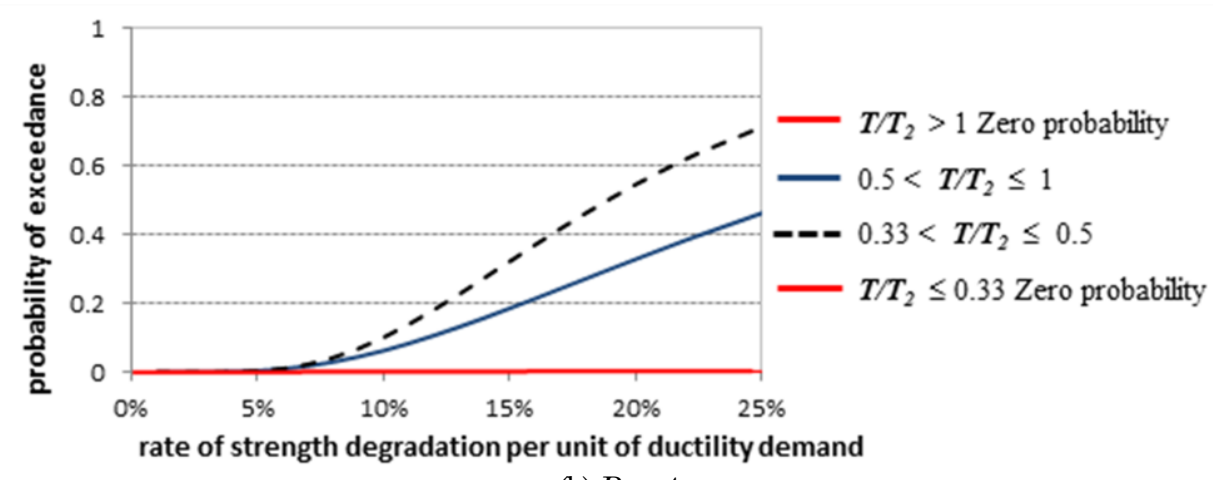

(b) $R_{\mu}=4$

Figure 12. Probability of Exceedance for $P D D$ of Asymmetrical Buildings

\section{Concluding Remarks}

A simple seismic assessment of buildings in regions of low to moderate seismicity has been developed based on the concept of the displacement-controlled behaviour. A generalised response spectrum model in bi-linear form was first developed to provide seismic response predictions assuming linear elastic behaviour. Parametric studies have been undertaken involving extensive time history analyses of inelastic systems with and without strength degradation. It has been shown that with a modest strength reduction factor of 2 , the system's inelastic displacement demand would typically be constrained by the Peak Displacement Demand (PDD) as indicated on the elastic displacement response spectrum for $5 \%$ damping.

The concept of displacement-controlled behaviour has been extended to structural systems that are subject to torsional actions arising from asymmetry. It has been found that a torsional amplification factor of $1.6\left(P D D=1.6 R S D_{\max }\right)$ can be applied for estimating the peak drift demands of asymmetrical buildings provided that the center of resistance is in alignment with the center of mass in the orthogonal direction.

It has been demonstrated in this study that the maximum drift demand on a building can be estimated based on the properties of the ground shaking without the need to undertake time consuming modelling and computations. The maximum drift demand can be compared to the displacement capacity for a quick assessment of its potential seismic risk to collapse.

\section{References}

1. Lam, N.T.K. and Chandler, A., Peak Displacement Demand of Small to Moderate Magnitude Earthquake in Stable Continental Regions, Earthquake Engineering and Structural Dynamics, 34, 2005, pp. 1047-1072.

2. Al Abadi, H., Lam, N.T.K. and Gad, E., A Simple Displacement Based Model for Predicting Seismically Induced Overturning, Journal of Earthquake Engineering, 10(6), 2006, pp. 775-814.

3. Kafle, B. Lam, N.T.K., Gad, E.F. and Wilson, J.L., Displacement Controlled Rocking Behaviour of Rigid Objects, Earthquake Engineering and Structural Dynamics, 40, 2011, pp. 16531669.

4. Doherty, K., Griffith, M.C., Lam, N. and Wilson, J., Displacement-based Seismic Analysis for outof-plane Bending of Unreinforced Masonry Walls, Earthquake Engineering and Structural Dynamics, 31(4), 2002, pp. 833-850.

5. Lam, N.T.K., Wilson, J.L. and Hutchinson, G.L., The Seismic Resistance of Unreinforced Masonry Cantilever Walls in Low Seismicity Areas, 
Proceedings Pacific Conference of Earthquake Engineering, Melbourne, Australia, 1995.

6. Lumantarna, E., Lam, N., Wilson, J. and Griffith, M., Inelastic Displacement Demand of Strength Degraded Structures, Journal of Earthquake Engineering, 14(4), 2010, pp. 487511.

7. Lumantarna, E., Lam, N. and Wilson, J., Bilinear Displacement Response Spectrum Model for Engineering Applications in Low and Moderate Seismicity Regions, Soil Dynamics and Earthquake Engineering, (in press).

8. AS 1170.4, Structural Design Actions-Part 4 Earthquake Actions, Sydney: Standards Australia, 2007.

9. EN 1998-1, Eurocode 8: Design of Structures for Earthquake Resistance-Part 1: General Rules, Seismic Actions and Rules for Buildings, BSI, 2004.
10. Federal Emergency Management Agency, NEHRP Recommended Provisions for Seismic Regulations for New Buildings and Other Structures Part I: Provisions (FEMA 450-1), Washington, 2003.

11. Lam, N.T.K., Wilson, J.L, Chandler, A. and Hutchinson, G., Response Spectral Relationships for Rock Sites Derived from the Component Attenuation Model, Earthquake Engineering and Structural Dynamics, 29, 2000, pp. 1457-1489.

12. Lam, N.T.K., Wilson, J.L. and Hutchinson, G.L., Synthetic Earthquake Accelerograms using Seismological Modelling: A Review, Journal of Earthquake Engineering, 4, 2000, pp. 321-354.

13. Idriss, I.M. and Sun, J.I., User Manual for SHAKE-91, University of California at Davis, USA, 1992.

14. Chopra, A.K., Dynamics of Structures-Theories and Applications to Earthquake Engineering, 2nd edition, NJ: Prentice Hall, USA, 2000. 